INTERNATIONAL JOURNAL OF MULTIDISCIPLINARY RESEARCH AND ANALySis

ISSN(print): 2643-9840, ISSN(online): 2643-9875

Volume 04 Issue 11 November 2021

DOI: 10.47191/ijmra/v4-i11-38, Impact Factor: 6.072

Page No.- 1717-1719

\title{
The Study of Cicadas in the Conditions of the Fergana Valley of Uzbekistan
}

\author{
A. G. Kojevnikova \\ Tashkent State Agrarian University
}

ABSTRACT: The article presents materials on the study of the cicadas Laodelphax striatellus Fall. and Muirodelphax aubei Perr.in the Fergana Valley, their morphological and biological characteristics, systematic position, distribution, harmfulness, food connections and peculiarities of their diagnosis.

KEYWORDS: Cicadas, species, composition, family, genus, species, Laodelphax striatellus Fall, Muirodelphax aubei Perr., diagnosis.

\section{INTRODUCTION}

As I.D. Mityaev points out [1], the useful value of cicadas for humans is very insignificant. There is evidence that some peoples eat large singing cicadas, considering them medicinal, or keep cicadas in cages for the sake of their peculiar singing.

It is proved that some species of cicadas, in places of their mass reproduction, play a significant role in the permeability of moisture and aeration of the soil, the underground work of their larvae. Larvae and imago of cicadas are a source of food for many animals and they play a certain role in biocenoses. Some species, due to their low abundance and low harmfulness, are not of great practical importance for humans. Most of the cicadas are pests of various agricultural plants [2, pp. 146-150].

As noted by D.A. Azimov, without deep knowledge of the fauna and development of the taxonomy of insects, as well as other groups of fauna and vegetation, it is impossible to solve further problems of protection and rational use of useful forms, as well as organization of plant protection [3, pp. 54-55].

Therefore, the study of cicadas and their diagnosis is not only theoretical, but also practical.

\section{THE MAIN FINDINGS AND RESULTS}

The territory of the Fergana Valley is characterized by a large amount of heat and a significant duration of the growing season in the summer, providing the cultivation of various cultivated plants. In general, the Fergana Valley presents the whole variety of natural conditions typical for Central Asia.

A large role in the study of cicadas in Central Asia, including in the Fergana Valley, belongs to G.K. Dubovsky [4, p. 215].

Information about cicadas damaging various cultures is available in the works of other authors [2, pp. 146-150; 5, p. $286 ; 6$, p. 45].

The emerging need to fully identify the harmful fauna of cultivated plants, a detailed study of their ecology and biology, will facilitate the improvement of modern plant protection, including the development of methods for express diagnostics of pests, forecasting the appearance and distribution of the most harmful species, the development of new biological plant protection products based on the study of entomophages, etc.

\section{RESEARCH OBJECT AND METHODS}

The material for this work was a 10-year study of cicadas in the conditions of the Fergana Valley of Uzbekistan. We used the generally accepted in entomology and special techniques.

\section{RESEARCH RESULTS}

Cycadids suck out juices from plants, apply ovipositor wounds on vegetative parts, and some species transmit viral diseases of various crops. Sometimes weakened plants are susceptible to damage by various diseases [1, p. 56; 2, pp. 146-150; 4, p. 215]. 


\section{The Study of Cicadas in the Conditions of the Fergana Valley of Uzbekistan}

Cicadids belong to the class of insects - Insecta, to the order of the isoptera - Homoptera. In addition to very short 3segmented antennae with terminal bristles and 3-segmented tarsi, they also differ in jumping hind legs and wing structure. These are insects with incomplete transformation. In their development, they go through 3 phases: egg, larva, imago [7, pp. 193194; 8, p. 79].

The Delphacidae Leach. is characterized by the fact that it includes small, less often medium-sized cicadas.

The head of representatives of this family is usually short; the keels on it are sometimes invisible. The wings are folded like a roof, often shortened. The apex of the hind tibia is equipped with a large movable spur.

These are exclusively inhabitants of herbaceous vegetation. They usually live on grasses in wet areas.

The larvae lead a lifestyle similar to adults. Older larvae usually hibernate, less often adults or eggs.

In the countries of Central Asia, 17 harmful species from the Delphacidae family have been identified.

At present, it is of practical importance to study harmful species of cicadas, from the family Delphacidae, representatives of the genus Laodelphax Fennah (Laodelphax striatellus Fall.) and the genus Muirodelphax Wagner (Muirodelphax aubei Perr.).

Harmful species of these genera are widespread in the republics of Central Asia and in Kazakhstan [1, p. 56; 4, p. 215].

Accurate diagnosis of these species is necessary in order to carry out scientifically based protective measures against them.

The genus Laodelphax Fennah, 1963, is distinguished by the following features:

Vertex rectangular, longer than its width, with slightly diverging lateral edges, rounded in front, protruding in front of compound eyes, with two pits in the lower part. The frons is twice as long as wide, with a median carina.

Two simple eyes lie in front of the compound eyes.

The first segment of the antenna is slightly longer than the second; the second segment bears a relatively long bristle.

Pronotum weakly dissected posteriorly, with three carinae, two of which diverge laterally and one in the middle. Scutellum convex with three carinae.

The wings of long-winged individuals are developed, upper leathery, long, rounded behind, lower transparent, long. In short-winged specimens, they reach the end of the abdomen or half of it, leathery, rounded at the ends, usually ellipsoidal in shape.

Hind tibiae with two spines. The spur is strong, flattened, oval, as long as the first segment of the tarsus, there is a complex comb, consisting of 20 teeth.

A typical representative of this genus is the numerous, ubiquitous species Laodelphax striatellus Fall.

According to I.D. Mityaev, in Kazakhstan it is a very numerous, ubiquitous species. It is not only a direct pest of seedlings of cereals in various regions, especially in the north, but also carries a viral disease of the bulging of oats and corn [1, $p$. 56].

Laodelphax striatellus Fall, in the Fergana Valley harms various cereals (oats, wheat, barley, corn, rice) and other crops. In addition, this species is known as a carrier of a number of viral plant diseases (bulging of oats and other cereals, red dwarf corn, dwarf and striped rice disease). Therefore, this pest must be known and be able to identify.

This insect can be identified by the following features.

Males of Laodelphax striatellus are black, but carinae, vertex, pronotum, and middle scutellum are white. The elytra are transparent with a black spot at the suture in the middle. The anal tube of the male is small, with teeth below. Aedeagus thin, slightly curved in profile, spear-shaped apex.

Females are orange-yellow. The size of the male and female is $1.7-4.0 \mathrm{~mm}$.

Our studies have shown that older larvae overwinter under the conditions of the Fergana Valley. The adults of them appear in early spring, in early or mid-March.

Laodelphax striatellus develops in 4-5 generations.

Laodelphax striatellus is especially abundant in August and September.

Species of the genus Muirodelphax Wagner, 1963, are characterized by the fact that they have processes of the anal tube, mostly contiguous. Hind margin of pygofer in the form of powerful lamellar angular lobes. Styli with angular projection on the inner edge at the base.

The cicada Muirodelphax aubei Perr., 1857, has a yellowish-brownish body, the abdomen is dark brown, with light longitudinal stripes. Aedeagus tubular, almost straight, with teeth in the upper half.

The dimensions of the short-winged male and female are 2.4-2.8 $\mathrm{mm}$, the full-winged male and female 3.9-4.2 $\mathrm{mm}$.

On the irrigated lands of the Fergana Valley, it occurs mainly in shaded biotopes. We registered the cicada on cultivated plants on wheat and barley.

Cicadas suck out the sap from the plant, as a result, with a large number; the plants wither and dry out [9, pp. 101-103]. 


\section{The Study of Cicadas in the Conditions of the Fergana Valley of Uzbekistan}

\section{CONCLUSION}

The study of cicadas is of practical importance, since many of them are agricultural pests.

Some species carry dangerous viral plant diseases and are under constant control.

As a result of research, we have identified relatively numerous species in the Fergana Valley (Laodelphax striatellus

Fall., Muirodelphax aubei Perr.) from the family Delphacidae Leach., Damaging cereals and other crops, for the practical activities of farms.

\section{REFERENCES}

1) Mityaev I.D. (2001) Cicadids of Kazakhstan (Homoptera, Cicadinea). - Publishing house "Science". - Alma-Ata: - p. 56.

2) Kozhevnikova A.G. (2000) Cycadids (Auchenorrhyncha) are pests of agricultural crops in Uzbekistan. Diss. Doctor of Biological Sciences: 03.00.09. - Tashkent: - pp. 146-150.

3) Azimov D.A. (1993) (edited) Insects of Uzbekistan. - Publishing house "Fan". - Tashkent: - pp. 54-55.

4) Dubovsky G.K. (1966) Cicadaceae (Auchenorrhyncha) of the Fergana Valley. - Publishing house "Fan". - Tashkent: - p. 215.

5) Yakhontov V.V. (1953) Pests of agricultural plants and products of Central Asia and their control. - Publishing house "Gosizdat". - Tashkent: - p. 286.

6) Sulaimanov Kh.A. (1972) Tsikadovye Karshi steppe // Coll. Ecology and biology of animals in Uzbekistan. - Tashkent: - p. 45.

7) Bey-Bienko G.Ya. General entomology. - Publishing house "Higher school". - Moscow: - pp. 193-194.

8) Kozhevnikova A.G. (2009) Cicadaceae (Auchenorrhyncha) damaging grain crops in the farms of the Andijan region // Materials of the scientific conference. "Actual problems of entomological science". - Tashkent: - p. 79.

9) Kozhevnikova A.G. Cycadids (Auchenorrhyncha) are pests of agricultural crops in Uzbekistan. Monograph. - Publishing house "Fan va texnologiyalar". - Tashkent: - pp. 101-103. 